\title{
Design and Setting up of a Laboratory Drive System with Remote Monitoring and Control
}

\section{Dimitrov}

Key Words: Asynchronous drive; soft starter; PLC; intelligent energy meter; remote monitoring and control.

Abstract. Systems for remote monitoring and control on energy consumption, efficiency and proper operation of the controlled objects are very often used in different spheres of industry, building automation, electricity distribution network etc. Various types of intelligent energy meters, PLCs and other control devices are involved in such systems. On the other hand, soft starters are widely used in industry and building automation for control on asynchronous drives when the speed regulation is not a mandatory requirement. They are cheaper than inverters and frequency converters and allow temporal reduction of the torque and current surge during start-up, as well as smooth deceleration. This is why the study of the principles of operation and setting up of intelligent energy meters, soft starters and PLC is very important. A laboratory system has been designed and built. An asynchronous motor is controlled by a soft starter and remote monitoring and control by contemporary devices has been provided. A methodology of design and setting up has been developed.

\section{Introduction}

Remote monitoring and control systems are very often used in industry and building automation. Centralized data acquisition and supervisory control of many dispersed objects are performed from a dispatcher center. Different intelligent devices are involved in the objects - measurement equipment, PLCs, sensors, actuators and many other devices are used for collecting information and executing commands. The development and deployment of such systems leads to increased efficiency and minimize energy consumption, as well as proper operation of the controlled objects [1-4].

The asynchronous motors are introduced in many fields of industry and building automation because of their minimized dimensions and weight, higher efficiency and enhanced reliability as opposed to DC motors. In most applications, inverters or frequency converters are used to regulate the speed of the drive [5-11]. On the other hand, many drives need to be started and stopped smoothly but its speed might be constant through the operating modes. Intelligent devices called "Soft starters" can be used in those cases [5-8, 12,13]:

- Conveyors and Conveyor belt systems can be smoothly started, avoiding jerk and stress on drive components.

- Fans and other systems with belt drives can be started slowly to avoid belt slipping.

- Pumps - the pressure surges can be avoided by the use of a soft starter.

- Compressors, Automatic doors, Small cranes, etc.

The soft starter is a device used with AC induction motors to temporarily reduce the torque and current surge during start-up and stop-down. The motor starts and stops gradually and smoothly in a controlled manner. This reduces the mechanical stress on the motor and shaft, as well as the electrodynamic stresses on the electrical distribution network, extending the lifespan of the system - the transient voltage drops that may affect other loads is reduced and the stability of the power supply is improved $[5-8,12,14]$.

Therefore, the study and examination of the listed contemporary equipment is very important. A laboratory drive system with remote monitoring and control has been designed and built. Different methods of setting up and testing have been developed. Finally, it should be noted that remote monitoring and control on asynchronous drives is often used when the motors are controlled by inverters or frequency converters $[2,9,11,15$ and 16$]$.

\section{Design of a Laboratory Asynchronous Drive System}

The laboratory system for asynchronous drive examinations is shown in figure 1. A $3 \mathrm{~kW}$ motor made in Bulgaria is used (table 1). A load of the motor can be changed by an electromagnetic brake (EMB), which has to be powered by an additional DC voltage source. The possibility of reverse is provided by two circuit breakers - F (forward - K1) and $\mathrm{R}$ (reverse - K2). The necessary locks and protection are also assured -3 poles thermal magnetic motor circuit breaker $A F$ $M C B$ GV2-ME14 (rated current $10 \mathrm{~A}$ and thermal protection adjustment range 6-10 A) [17], as well as three fast acting fuses $F$ (rated current $10 \mathrm{~A}$ ). An opportunity for electrodynamic brake is also provided by the transformer Trf, rectifier and circuit breaker K. A transformer $220 \mathrm{~V} / 36 \mathrm{~V}$ has been selected and the rectifier DC voltage is $32 \mathrm{~V}$ at current $1 \mathrm{~A}$, acceptable for the diodes. Circuit breakers and buttons designed for operation in $220 \mathrm{~V}$ circuits have been also selected.

The motor is controlled by Altistart 01 ATS01N2 soft start/soft stop unit developed by Schneider Electric Company $[18,19]$. It controls the motor power supply to limit the starting current and for deceleration and helps to prevent mechanical shocks, which cause wear and tear, and subsequent maintenance work and production downtime. The voltage is controlled by reverse-parallel-connected thy- 
ristors which are connected in series with the line voltage applied to the star-connected motor. An internal bypass relay in steady-state operation is also featured.

These devices are equipped with three potentiometers for setting the starting and deceleration time $\left(t_{a c c}\right.$ and $\left.t_{d c c}\right)$ and for adjusting the starting voltage threshold according to the motor load $\left(U_{i n}\right)$. Two logic inputs provide Run/Stop commands and a logic input can be used for the Boost function (+24 $\mathrm{V}$ positive logic). One logic output and one relay output indicate the drive condition. A green LED indicates that the unit is powered up and a yellow LED indicates that the motor is powered at nominal voltage $[13,18]$.

The appropriate model is selected according to the technical data of the asynchronous motor (see the table 1). Altistart ATS01N2**QN is available for voltage $380 \mathrm{~V}$. The model ATS01N209QN for nominal current 9A is appropriate for motors with power of 3-4 kW (the main technical parameters are given in table 2) [19].
The logical inputs and outputs of the soft starter are connected to the PLC Simatic S7-200 [20]. TP177micro Touch Panel is configured for Start/Stop and Boost commands that are transmitted through the PLC to the soft starter [21]. Threewire control is realized - the run and stop commands are controlled by different logic inputs. The LI1 and LI2 logic inputs are connected to two logic outputs of the PLC (for ex. Q1.0 and Q1.1). The relevant buttons are configured on the touch panel - a normally closed button for Stop command (associated to the Q1.0 and LI1) and a normally open button for Run command (associated to the Q1.1 and LI2). A switch is also configured on the Touch Panel for the Voltage Boost function via third logic input of the soft starter (connected to the digital output Q0.7 of the PLC) - activating this input enables the function for supplying a starting overtorque capable of overcoming any mechanical friction. When the input is at state " 1 ", the function is active and the starter supplies the rated voltage to the motor for a limited time $(200 \mathrm{~ms})$ before starting.

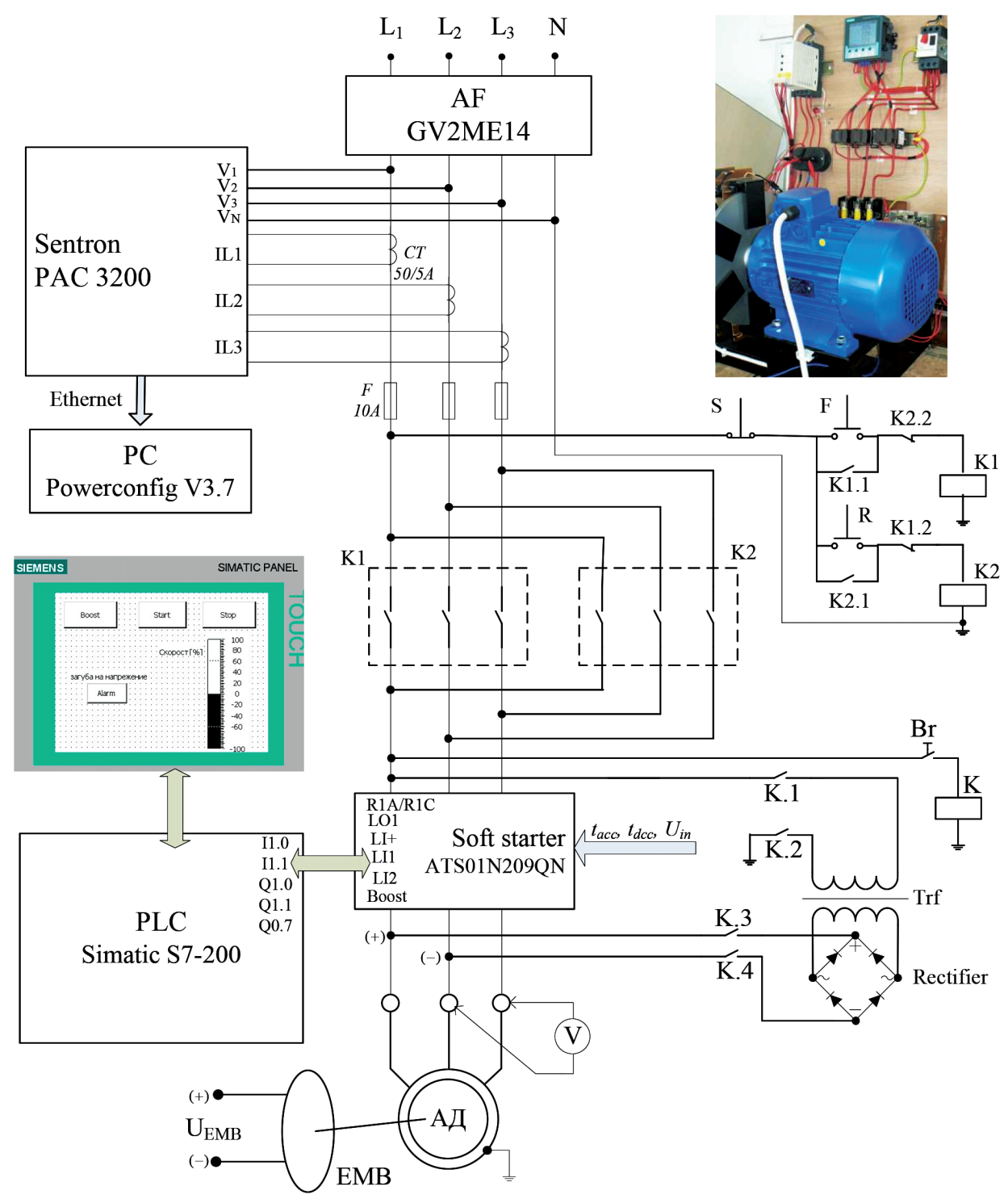

Figure 1. Laboratory system for remote monitoring and control of asynchronous drive with soft starter (electrical scheme and exterior view of the drive) 
Table 1. Technical data of the asynchronous motor

\begin{tabular}{|l|l|}
\hline 4-pole Asynchronous Motor $(\mathrm{p}=2)$ & Frame size AT 100 L4, AL/AL \\
\hline Rated Voltage, Frequency & $220 \mathrm{VD} / 380 \mathrm{VY}, 50 \mathrm{~Hz}$ \\
\hline Rated Output Power & $3 \mathrm{~kW}$ \\
\hline Rated Speed & $1430 \mathrm{rpm}(\mathrm{no}=1500 \mathrm{rpm})$ \\
\hline Rated Torque & $20 \mathrm{Nm}$ \\
\hline Rated Current & $12,3 \mathrm{~A}(\mathrm{D}) ; 7,1 \mathrm{~A}(\mathrm{Y})$ \\
\hline Power Factor at 4/4 Load & 0,78 \\
\hline Efficiency at 4/4 Load & $82,3 \%$ \\
\hline Weight & $23,3 \mathrm{~kg}$ \\
\hline
\end{tabular}

Digital inputs of the PLC are used for receiving the information about drive condition. The logic output LO1 of the soft starter indicates the end of starting when the bypass relay has been switched on and the motor has reached nominal speed. A bar is configured on the Touch Panel and shows the motor speed. The Fault relay (built into the soft starter) opens when a fault is detected: the relay contact R1A-R1C closes with the Run command and opens when the motor voltage is around 0 with a decelerated stop or on a fault. An alarm is configured on the Touch Panel and will indicate a fault.

Table 2. Main technical parameters of the soft starter ATS01N209QN

\begin{tabular}{|l|r|}
\hline Power supply & 342...456 V; $47,5 \ldots 63 \mathrm{~Hz}$ \\
\hline Current & 9 A rated operating current; 30A starting current at nominal load \\
\hline Power dissipated & $4 \mathrm{~W}$ (at full load at end of starting); $94 \mathrm{~W}$ (in transient state) \\
\hline $\begin{array}{l}\text { Starting time } t_{a c c} \\
\text { (acceleration time) }\end{array}$ & $\begin{array}{c}\text { Adjustable } 1 \ldots 10 \mathrm{~s} \\
\text { Maximum number of cycles per hour: }\end{array}$ \\
\hline Deceleration time $t_{d c c}$ & Adjustable $1 \ldots 10 \mathrm{~s}$ \\
\hline Initial Voltage & $U_{\text {in }}=30-80 \% U_{n}$ \\
\hline Starting torque & $30 \ldots 80 \%$ of starting torque of motor connected directly on the line supply \\
\hline
\end{tabular}

Measuring equipment with high accuracy is also provided in the laboratory system. The power monitoring device Sentron PAC3200 developed by Siemens offers an analysis of the electrical system's current consumption and power flows [22-24]. It is connected direct in the voltage system. For measuring current, three 50/5 A current transformers $\mathrm{CT}$ are used (the maximum current at starting is 50 A). In addition, the Sentron PAC 3200 has a multifunctional digital input and digital output (simple logic functions for alarming can be set up).

Sentron PAC3200 precisely and reliably detects the power values of electrical consumers and provides important measured values for assessing the system state and power quality. This device has a range of useful monitoring, diagnostics and service functions, a two-tariff active energy and reactive energy counter (imported and exported energy), a universal counter, and a working hours counter for monitoring the running time of connected loads. All the relevant system parameters can be shown on the large graphical LC display that permits reading even from a distance [24]:

- Voltage (Phase-neutral $-U_{1-n} / U_{2-n} / U_{3-n}$ and Phase-phase $\mathrm{U}_{1-2} / \mathrm{U}_{2-3} / \mathrm{U}_{3-1}$ ).

- Currents (per phase $-\mathrm{I}_{1} / \mathrm{I}_{2} / \mathrm{I}_{3}$ ).
- Active power (per phase $- \pm \mathrm{P}_{1} / \pm \mathrm{P}_{2} / \pm \mathrm{P}_{3}$ and total $\left.\pm \mathrm{P}_{\text {total }}\right)$.

- $\quad$ Reactive power (per phase $- \pm \mathrm{Q}_{1} / \pm \mathrm{Q}_{2} / \pm \mathrm{Q}_{3}$ and total $\left.\pm \mathrm{Q}_{\text {total }}\right)$.

- Apparent power (per phase $-\mathrm{S}_{1} / \mathrm{S}_{2} / \mathrm{S}_{3}$ and total $\mathrm{S}_{\text {total }}$ ).

- $\quad$ Power factor (per phase - $\left|\mathrm{PF}_{1}\right| /\left|\mathrm{PF}_{2}\right| /\left|\mathrm{PF}_{3}\right|$ and total $\left.\left|\mathrm{PF}_{\text {total }}\right|\right)$.

- Total harmonic distortion (THD) for voltage and current (per phase - THD- $\mathrm{U}_{1} /$ THD- $\mathrm{U}_{2} / \mathrm{THD}_{3} \mathrm{U}_{3}$ / THD-I / THD-I / THD-I ${ }_{3}$ ).

- Frequency f.

- Phase unbalance (Voltage).

- Min. / max. values (Voltage / Current / Power / Power factor / THD / Frequency / Three phase average voltage and current / Three phase average rating for active and reactive power), a possibility of reset is provided.

The combination of four function keys makes intuitive user prompting possible. The integral Ethernet interface is provided for easy integration into any local or remote monitoring system. In the laboratory system, it is used for communication between the device and a computer (PC). Modbus 
TCP Ethernet protocol is used (10 Mbps) and the relevant software product Powerconfig V3.7 has been installed on the PC [25]. The Sentron PAC3200 transmits measured values to the supervisory system, where the data can be further processed for display and control (there is an opportunity of exporting to Excel tables). The configuration of the parameters can be done either directly from the front display or through the communication interface using the PC.

\section{Possibilities of Testing and Examinations}

The laboratory system offers various possibilities of research and implementation into practice many laboratory exercises, for example:

- Training the programming skills for setting-up the soft starters, intelligent measuring devices, PLCs and touch screens, as well as the communication between these devices and the PC (knowledge of the relevant software products is necessary).

- Remote monitoring of the drive operation and analysis of the electrical system's current consumption and power flows.

- Study of the impact of start-up and ramp-down time on drive performance.

- Synthesis of algorithms for optimal control on the drive systems.

- Evaluation of the PLC's possibilities of using it in the drive systems for efficiency optimization.

- Examination of the asynchronous drive at variable load, etc.
The existence of PLC with touch panel and PC connected to the Sentron PAC3200 allows for simultaneous drive control, monitoring and parameters' tracing and capturing. Methods for some laboratory tests by instrumentation with high accuracy are developed:

- Determination of the static mechanical and electromechanical characteristics of the asynchronous drive [26]

(1) $\omega=f(M), \omega=f(I)$.

- Determination of the characteristics that show the change of energetic parameters of the drive (power factor, efficiency, THD, etc.) at the different settings of the soft starter

$$
\begin{aligned}
& \cos \varphi=f\left(t_{a c c} ; t_{d c c} ; U_{i n}\right), \eta=f\left(t_{a c c} ; t_{d c c} ; U_{i n}\right), \\
& \text { (2) } T H D_{I}=f\left(t_{a c c} ; t_{d c c} ; U_{i n}\right), \\
& T H D_{U}=f\left(t_{a c c} ; t_{d c c} ; U_{i n}\right) .
\end{aligned}
$$

- Capturing the dynamic characteristics when starting, stopping and changing the load

$$
\begin{aligned}
& \text { (3) } I=f(t), P=f(t), Q=f(t), U=f(t) \text {; } \\
& \text { (4) } \cos \varphi=f(t), T H D_{I}=f(t), T H D_{U}=f(t) \text {. }
\end{aligned}
$$

Remote monitoring of the drive operation is shown in the figure 2. The Power Factors are selected to be monitored - the power supply Lines 2 and 3 are checked in the menu and their graphics are plotted. When the drive is not running these parameters are not defined. During acceleration the Power Factor is very big because the starting torque significantly exceeds this one in steady state operation. Thus an experimental verification of the theoretical dependencies is made.

Any other parameters can be selected and their moment values could be watched.

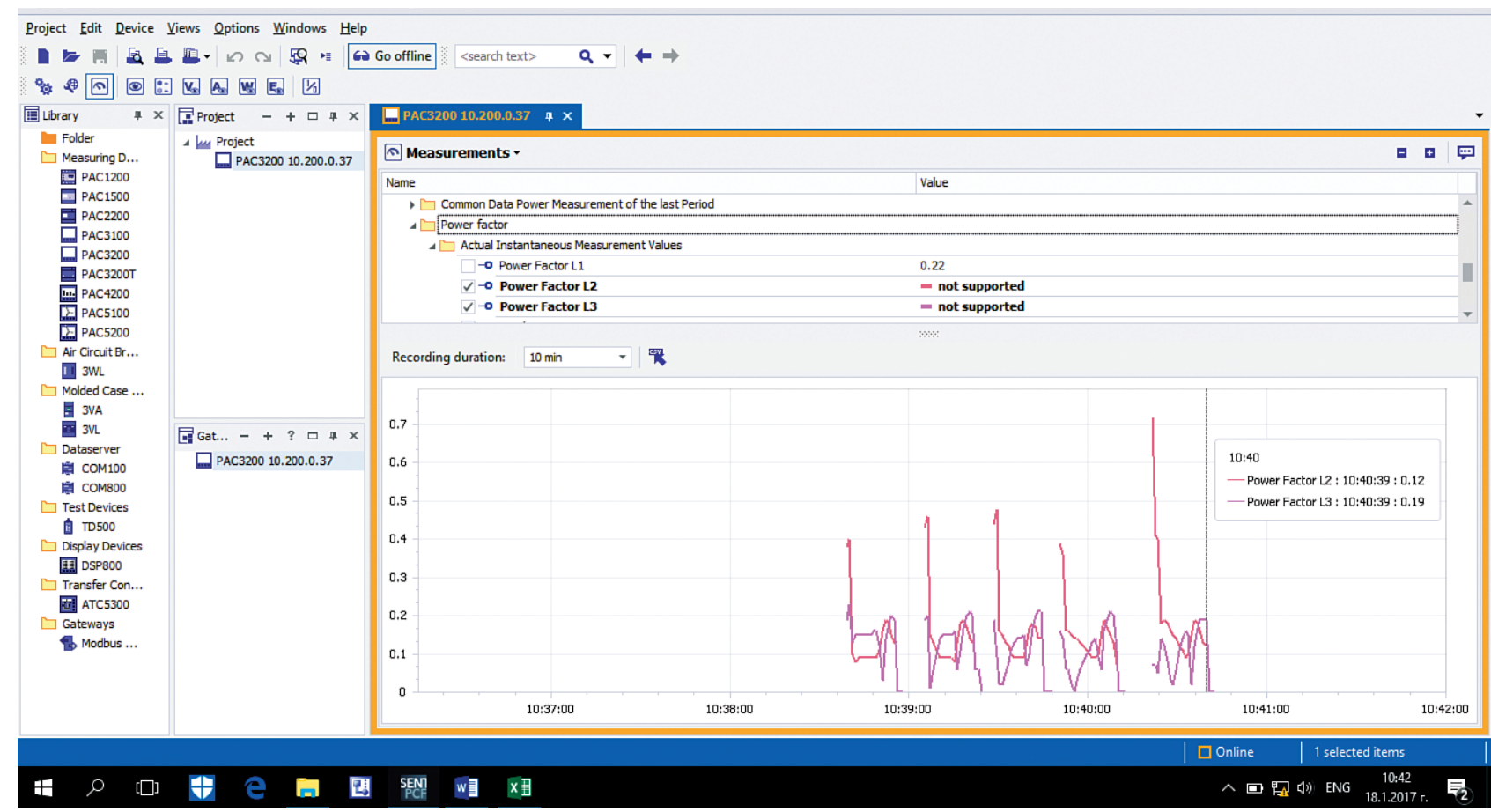

Figure 2. Software Powerconfig V3.7 - monitoring of the drive parameters 


\section{Conclusion}

Intelligent energy meters are implemented in many systems for remote monitoring and control in industry, building automation, transport, etc. They offer possibility of real time remote watching the parameters of the controlled objects by the dispatcher. Thus they are used for observing the proper operation and increasing the efficiency.

PLCs are often implemented as primary components in very big part of control system configurations. The PLCs Simatic series offer maximum automation at minimum dimensions - it is compact, fast and highly powerful, feature great communications capabilities and it is based on very user-friendly software and hardware. They are used for complex automation tasks and finds application in many branches of industry, power engineering and transport.

Soft starters are also widely used in industry for control on asynchronous drives when the speed regulation is not a mandatory requirement. They are cheaper than inverters and frequency converters and allow temporal reduction of the torque and current surge during start-up, as well as smooth deceleration. This is why they are used in many typical applications - pumps, air coolers, compressor, conveyors and other belt systems, automatic doors, small cranes, etc. Therefore they can also be used in electric vehicles for control on auxiliary machines (pumps, fans, compressors, etc.).

These advantages cause to teaching the students how to use and program soft starters, PLCs and contemporary measuring devices. The developed laboratory system offers various possibilities of research and implementation into practice many laboratory exercises, for example:

- Determination and capturing of different drive characteristics. Thus an experimental verification of the theoretical dependencies can be made.

- Selecting the right scheme and settings of the drive components depending on specific application.

- Study of the influence of the start-up and rampdown time on the drive performance.

- Training the programming skills for setting-up contemporary measuring and control devices and their communication through the networks, as well as their using in the control systems for monitoring and analyzing the electrical system's parameters.

- Synthesis of algorithms for optimal control on the drive systems depending on the load torque, as well as evaluation of possibilities of efficiency optimization.

\section{References}

1. Stouffer, K., V. Pillitteri, S. Lightman, M. Abrams, A. Hahn. Guide to Industrial Control Systems (ICS) Security. NIST Special Publication 800-82, USA, 2015.

2. Synco - Enhanced Comfort and Energy Efficiency. Siemens Switzerland Ltd., 2013.

3. Dimitrova, E. A. Building Automation and Control Systems. Academic Journal Mechanics, Transport, Communications, 14, 2016, 3/2, Art. ID 1395, XI-26-XI-31, ISSN 1312-3823.

4. Dimitrova, E. A. Conceptual Description of the Processes of Remote Control and Monitoring of Mobile Objects. - Scientific Journal Mechanics, Transport, Communications, 14, 2016, 3/2, Art. ID 1394, XI-22-XI-25, ISSN 1312-3823.

5. Hughes, A. Electric Motors and Drives -Fundamentals, Types and Applications. Third Edition, Elsevier Ltd., 2006.

6. Bakshi, U. A., M. V. Bakshi. Electrical Drives and Control. Technical Publications Pune, India, 2009.

7. Boldea, I. S., A. Nasar. Electrical Drives. CRC/Taylor \& Francis Group, NY, 2006.

8. De, N. K., P. K. Sen. Electric Drives. Prentice Hall of India, 2006. 9. Products for Totally Integrated Automation and Micro Automation. Siemens, Catalog ST 70, 2009.

10. Sinamics G120 - The Modular Inverter - Energy-efficient. Safe and Communication Capable. Siemens, 2009.

11. ABB Drives and Controls - The Green Guide to More Profitable Business. ABB, 2016.

12. The Essential Guide of Automation \& Control. Schneider Electric, 2012.

13. Soft Starts for Single-Phase and Three-Phase Asynchronous Motors. Catalog, Schneider Electric, 2011.

14. Juraitis, S., R. Rinkevičiene, A. Smilgevičius. Experimental Investigation of Electric Drive Dynamics". 10th International

Symposium „Topical Problems in the Field of Electrical and Power Engineering“, Pärnu, Estonia, 10-15 January 2011, Proceedings, 21-24.

15. Sekoulov, L., T. Lalev, G. Pavlov, Y. Isaev, M. Tomcheva. Experimental Study on the Energy Performance of the Electrical Bus which is Operated in Sofia. - Scientific Journal Mechanics, Transport, Communications, 13, 2015, 3/3, Art. ID 1252, X-60-X-66, ISSN 1312-3823.

16. Dimitrov, V., E. Dimitrova. Using PLC for Control on Asynchronous Drives - Laboratory Simulator. 51-st International Scientific ICEST 2016, Ohrid, Macedonia, 28-30 June 2016, Proceedings, ISBN 978-9989-786-78-5, 471-474.

17. TeSys GV2-Circuit Breaker-thermal-magnetic - 6...10 A. Product Data Sheet, Schneider Electric, 2016.

18. Soft Starters Altistart 01 for Asynchronous Motors. Catalog, Schneider Electric, 2014.

19. ATS01N209QN Soft Starter for Asynchronous Motors. Product Data Sheet, Schneider Electric, 2011.

20. SIMATIC S7-200 - Programmable Controller. System Manual, Siemens, 2008.

21. SIMATIC HMI Device TP 177 micro (WinCC Flexible). Operating Instructions, Siemens, 2005.

22. SENTRON PAC Power Monitoring Devices. Siemens, 2009.

23. SENTRON PAC3200. Technical Specification, Siemens, 2011.

24. SENTRON PAC3200. Manual, Siemens, 2008.

25. http://w3.siemens.com/powerdistribution/global/en/lv/portfolio/pages/powerconfig.aspx.

26. Dimitrov, V. Development of Laboratory System for Electrical Drives Examinations. - Academic Journal Mechanics, Transport, Communications, 13, 2015, 3/3, Art. ID:1246, X-24-X-29, ISSN 1312-3823. 
Manuscript received on 07.07.2017

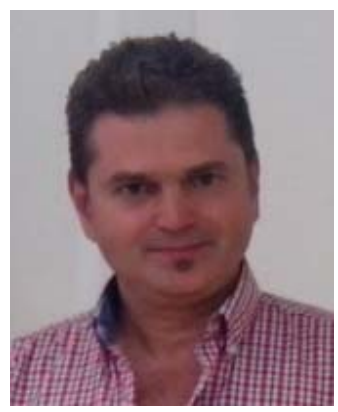

Vasil Dimitrov received his engineering M.Sc. degree in Automation of Electrical Drives in June 1991 from the Technical University of Sofia. He received a Ph.D. degree in May 2013 from Todor Kableshkov University of Transport - Sofia. In October 2014 he became Assoc. Prof. at Todor Kableshkov University of Transport - Sofia, Faculty of Telecommunications and Electrical Equipment in Transport. His research interests are in field of contemporary systems for control on electrical drives in transport and industry, including adaptive control on asynchronous drives, as well as of SCADA systems for remote control of dispersed objects in different sectors of the economy.

Contacts: Todor Kableshkov University of Transport - Sofia, Bulgaria

Department of Power Engineering and Electrical Equipment in Transport

158 Geo Milev St., 1754 Sofia e-mail:vdimitroff@abv.bg 